\title{
A Research Framework of Disaster Traffic Management to Smart City
}

\author{
Dedy Hartama, Herman Mawengkang, Muhammad Zarlis \\ Universitas Sumatera Utara, Medan, Indonesia \\ dedyhartama@amiktunasbangsa.ac.id, \\ hmawengkang@yahoo.com,m.zarlis@usu.ac.id \\ Mhd. Furqan, Dahlan Abdullah \\ Faculty of Computer Science \\ Universitas Sumatera Utara \\ Medan, Indonesia \\ mhdfurqan@gmail.com,dahlan.unimal@gmail.com
}

\author{
Rahmat Widia Sembiring \\ Politeknik Negeri Medan \\ Medan, Indonesia \\ rahmatws@yahoo.com \\ Robbi Rahim \\ School of Computer and Communication Engineering \\ Universiti Malaysia Perlis \\ Perlis, Malaysia \\ usurobbi85@zoho.com
}

\begin{abstract}
Safe City as part of Smart City, covers all aspects of safety within the city. Safe City is the integration of technology and the natural environment enhances the effectiveness of the process of handling the threat of crime and terror, to enable the availability of a healthy environment for citizens, and access to health, rapid response to emergencies. One aspect contained in the safe city is the evacuation support which includes disaster traffic management model. The purpose of this paper is to develop a research framework for disaster traffic management model with contra flow and zone scheduling, in order to minimize evacuation time and avoid congestion in the evacuation process.
\end{abstract}

Keywords-Safe City, Smart City, Evacuation, Contra Flow, Zone Scheduling

\section{INTRODUCTION}

According to Caragliu et al. [1], a city is said to be smart whenever human capital investment and information and communication technology (ICT) encourage sustainable economic growth and high quality of life, with wise, participatory and resource management. As in [2], Smart City seeks to improve performance through the implementation of flexible and efficient, sustainable networks and traditional services using information technology, digital and telecommunications, and is expected to create a city which is greener, safer, faster and more friendly.

Smart City is seen as a concrete and workable improvement effort in many parts of the world. For example, priorities in Northern Europe with a minimal crime will be different from those near the equator. In general, the problem solved is described in several key areas [3].

The focus of this research is the handling of a safe city. Aspects of Smart City by [2] and [4], consisting of Smart Transport, Smart Energy, Smart Technology, Smart Living, Smart Environment, Smart Citizens and Education, Smart Economy, Smart Government, and Safe City.

Safe City as part of Smart City, covers all aspects of safety within the city. On the other hand, Smart Technology has many uses in the safety field to build a Safe City system. Safe City is the integration of technology and the natural environment that enhances the effectiveness of the process of handling the threat of crime and terror, to enable the availability of a healthy environment for citizens, and access to health, rapid response to emergencies [5]. Another aspect is evacuation support. [6] discusses the application of Disaster Traffic Management to support Evacuation Support. Where the evacuation process should minimize time delay and maximize level of security.

The most commonly used evacuation strategy for traffic management is the use of Shoulder-Lane, contraflowing traffic and gradual evacuation [6]. [7] uses the Shoulder-Lane line to accommodate traffic spikes in emergency evacuation plans. They develop urban and rural plans, each operating with a Shoulder-Lane evacuation path. With some drawbacks in its application.

Contra-flow has been commonly used in traffic management by changing traffic lanes during peak hours [8]. Various current Contra-Flow techniques are like One-Lane, Two-Lane, and All-Lane Contra-Flow. In general, the implementation of Contra-Flow during the evacuation process is to reverse all In-Bound lines into Out-Bound lanes. The OutBound Lane line is generally a busy line, and In-Bound Lane is a relatively empty line of users [9].

In the event of a disaster, the population is at risk of being evacuated to safety as soon as possible using the highway as its main mode. An effective traffic management strategy is required to manage the increasing demand for roads significantly during evacuation and contra-flow strategies. Under these conditions, the Intelligent Transportation Systems (ITS) Tool can be applied, such as transmitted data using current and future communication technologies[10].

The research conducted by [9], produced several scenarios that could be used to support the Contra-Flow strategy, particularly those related to the utilization of In-Bound and OutBound Lane. Existing issues will be more difficult when there are several Out-Bound Lane leads to the same path, which will certainly lead to congestion when the evacuation process should be done as soon as possible [11]. 
The development of real-time evacuation model is very important because can avoid injuries and save lives[12]. Research conducted by [13] tries to overcome this congestion problem by mapping and describing them across neighborhoods.

According to [14], to implement contra-flow operations, there are two main issues to be decided, namely Optimal Contraflow Lane Configuration Problem (OCLCP) and Optimal Contraflow Scheduling Problem (OCSP). OCLCP aims to determine switchable portable candidates to minimize traffic threshold and OCSP aims to determine the start time and duration of operations.

The first research on OCSP mapping has been done by [15], which suggests that there are two approaches that can be used: zone scheduling and flow scheduling. In zone scheduling, zone settings are based on importance. Zones can be set so that a zone is only not allowed to be evacuated until a focused zone has been evacuated or evacuation time of each zone can be set by time. On the other hand, Flow Scheduling is a scheduling process based on the availability of evacuation facilities (vehicle-based) [16].

Research conducted by [16] has combined the application of Contra-Flow with the concept of Flow Scheduling. The focus observed is the optimization of the use of evacuation means (Vehicle-Based). Previous research conducted by [17] has used the concept of contra-flow which is equipped with the ability to predict the number of users for each zone traffic. In a study conducted by [12] the behavior of the users was unpredictable during the evacuation process. From a number of studies, no one has discussed the Contra-Flow linked to Zone Scheduling in relation to minimizing evacuation time and avoiding congestion in the evacuation process in particular When applied to some contra-flow strategies.

\section{Methodology}

This study discusses the issues of Contra-Flow and Zone Scheduling that are used in the evacuation process, which is included in the type of OCSP optimization. The problem of Contra-Flow and Zone Scheduling is basically a matter of BiLevel Programming. Bi-Level Programming issues can be divided into Upper Level and Lower Level. Upper-level is an integer programming model that aims to minimize travel time by integrating contra-flow with zone scheduling while lower level is a traffic simulation model that measures the response of users to the solution offered. This Bi-Level Programming problem can be transformed into integer programming by considering to the upper level aspect while the lower level is neglected.

\section{A. Data Source}

The data source for the evacuation problem that will be used in this research is the CBD area of Singapore provided in the Microscopic Simulation Tool named PARAMICS. The data in the CBD area of Singapore itself is collected by [18]. The CBD area of Singapore has 2046 links, 1050 nodes, and 36 zones.

\section{B. Research Process}

The phase of the research process can be seen in Fig. 1.

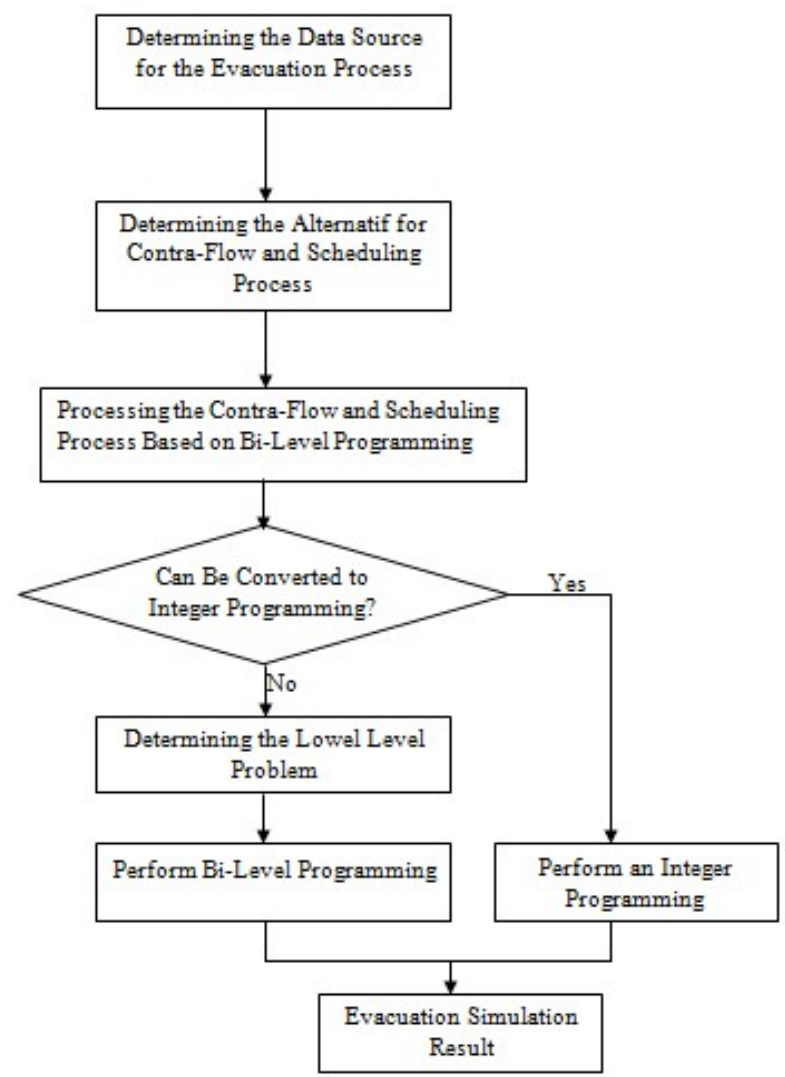

Fig. 1. Phases of the Research Process

\section{Safe City}

Smart City is a city where there are censors and computer devices scattered wherever humans as users are located and available to anyone in the place that enables more efficient urban management processes, simplify the flow of information, and optimize the use of infrastructure [18].

Smart City can be divided into several key areas [3] as shown in Fig. 2.

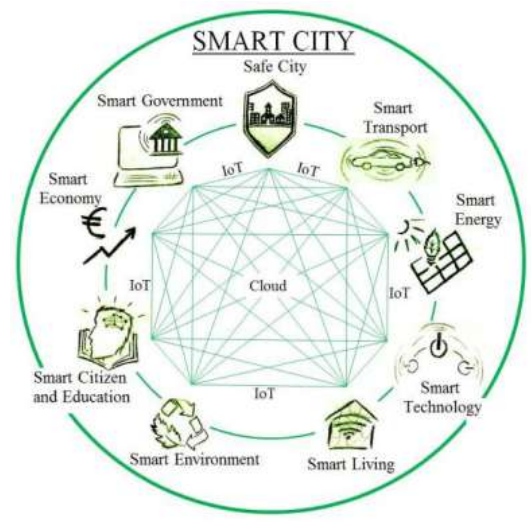

Fig. 2. Smart City's Main Field Division

\section{Safe City}

Fig. 2. shows that Smart City consists of several aspects such as Smart Transport, Smart Energy, Smart Technology, Smart Living, Smart Environment, Smart Citizens and Education, Smart Economy, Smart Government, and Safe City. 
Safe City as a part of smart city has been put forward for a long time based on smart city vision as a future city center, designed with safety aspects, ensuring environmental sustainability and efficient utilization of resources such as electricity, water, transportation, And other resources designed, built and maintained, utilizing integrated technological advances and integration of sensors, electronic equipment and networks connected with computerized systems comprising of databases, tracking facilities and algorithms for decision making [19].

According to [5], Safe City is a concept and solution offered by information and communication technology that integrates a number of aspects of Information and Communication Technology such as broadband infrastructure, Internet of Things (IoT), cloud computing, and big data, aiming to increase the safety level of all citizens.

Safe City should have the following features [3].

1. Healthcare.

2. Smart Traffic Systems and Routes.

3. Smart Safety Systems for Surveillance, Search, Detection, and Identification.

4. Smart systems of crisis management to support decisionmaking, early warning, monitoring, and forecasting.

5. Centrally operated units of police and Integrated Rescue System.

6. Safe internet connection and data protection.

7. Centers of data processing.

\section{E. Bi-Level Programming}

The Bi-Level programming model is considered to be the most suitable model for transportation investment decisionmaking issues because the bi-level structure reflects the fact that there are two types of decision makers in the transport system: one side decides the configuration of the evacuation transport route and the other decides the current pattern in the network.

\section{F. Disaster Traffic Management}

One important feature of Safe City is the availability of Integrated Rescue System [3], where one important aspect of the Integrated Rescue System is the availability of the Disaster Traffic Management System which aims to achieve quick readiness and response to threats or emergency emergencies [5].

Disaster Traffic Management consists of 5 (five) main strategies, namely [21]:

1. Strategy to avoid or reduce unnecessary car movement.

2. Strategies to Increase the usefulness of vehicles from a mode of transportation.

3. Strategy to change the mode of transportation that is individual to mass transportation mode.

4. Strategy to improve the distribution of space based on traffic volume.

5. Strategies to improve time distribution based on traffic volume.

6. Strategy to increase the supply capacity of a mode of transportation.

7. Strategy to reduce traffic accident.
8. Strategies to enhance integration between different modes of transportation.

9. Strategies to reduce disruption to traffic flow.

\section{G. Contra-Flow}

Contra-Flow operations are performed by reversing multiple lanes from underutilized roadways to cope with the sudden increase in traffic flow from one busy side. Contra-Flow is a highly effective dynamic traffic management strategy, since significant capacity gains can be gained without the need to build additional channels [22].

Various current Contra-Flow techniques are like One-Lane, Two-Lane, and All-Lane Contra-Flow [9]. As for Collins [12], there are several Contra-Flow Strategies as follows.

1. All Lanes Outbound

2. One lane reversed, one lane inbound for emergency / service vehicle entry only

3. One lane reversed, one lane inbound for traffic only

4. One lane reversed and use of outbound left shoulder lane

The four strategies can be seen in Fig. 3.

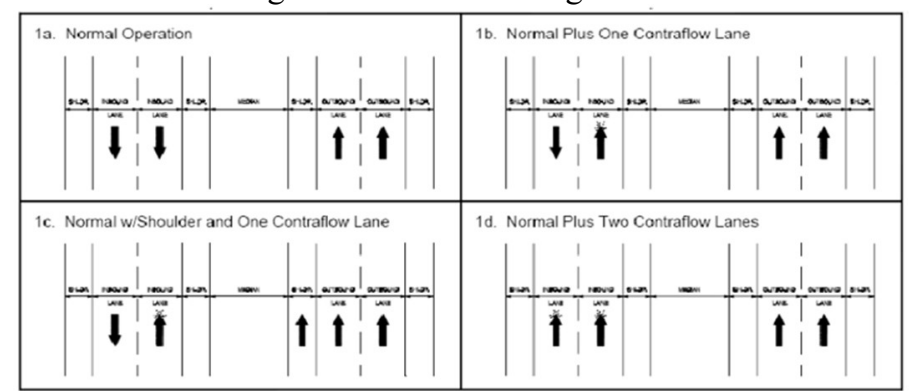

Fig. 3. Contra-Flow Strategy

\section{RESULTS AND DISCUSSION}

Suppose $A_{1}$ is the set of links from the Central Business District (CBD), where $A_{1} \subseteq A$ and $A_{2}$ is a set of candidate links that will be used to implement Contra-Flow operations. The Candidate Link in the set is usually identified by transport agents and traffic engineers who have information about possible bottleneck links that can generate congestion and in this study sourced from existing Historical Traffic Flow. For the record, practically the set $A_{2}$ may not be identical to the set $A_{1}$. Also given time period denoted as $[0, T]$ is necessary when operating the Contra-Flow.

The time period is assumed to be discrete for homogeneous intervals where $t$ represents the interval-minutes with $t \in\{1, \ldots, T\}$. There are three decision variables in this issue and are defined as follows [14].

$x_{i j}$ : The start time (within the time interval) of the ContraFlow operation for the link $(i, j) \in A_{2}$.

$y_{i j}$ : Time over (within the time interval) of the Contra-Flow op for the link

$(i, j) \in A_{2} z_{i j}^{k}=\left\{\begin{array}{ll}1, \text { if lane } k \text { of link }(i, j) \text { is chosen to reverse } \\ \text { travel direction } \\ 0, \text { otherwise }\end{array},(i, j) \in A_{2}\right.$ and $k=1,2, \quad, l_{i j}$ 
To simplify understanding, Suppose it represents the row vector of start time, finish time, and binary decision variable for the path transfer scheme from inbound to outbound for all links involved and can be written as Equation (2).

$$
\begin{aligned}
& \mathbf{x}=\left(x_{i j},(i, j) \in A_{2}\right), \mathbf{y}=\left(y_{i j},(i, j) \in A_{2}\right) \\
& \mathbf{z}=\left(z_{i j}^{k},(i, j) \in A_{2}, k=1,2, \ldots l_{i j}\right)
\end{aligned}
$$

Considering from traffic security and operational feasibility, there are several constraints that need to be defined for the problem. First, we must take into account the minimum time for a delay that is denoted as $\bar{T}_{i j}$ and the maximum time for the Contra-Flow operation to be denoted as $\hat{T}_{i j}$. This constraint can be seen in Equation (3).

$$
\bar{T}_{i j} / n \leq y_{i j}-x_{i j} \leq \hat{T}_{i j} / n,(i, j) \in A_{2}
$$

$$
\text { Where } x_{i j}, y_{i j} \in\{1,2, \cdots, T / n\},(i, j) \in A_{2}
$$

Note that $0 \leq \bar{T}_{i j}, \hat{T}_{i j} \leq T$

The value of $\bar{T}_{i j}$ and $\hat{T}_{i j}$ can be determined based on the policy of the appropriate authorities in accordance with the traffic conditions of each area. In addition, there is also the possibility of changing the flow of traffic from the candidate link from Median Lane to Shoulder Lane. This constraint can be seen in Equation (4).

$$
z_{i j}^{1} \leq z_{i j}^{2} \leq \cdots \leq z_{i j}^{l_{i j}},(i, j) \in A_{2}
$$

In the emergency situations where there are two or more candidate links used in the Contra-Flow operation that are connected to the same outgoing path as an evacuation route $\left(A_{2}\right.$ $A_{2}$ ). Only one of them is allowed to change the course of their journey. This constraint can be found in Equation (5).

$$
z_{i j}^{l_{i j}-m}+z_{j i}^{l_{j i}-m} \leq 1,(i, j) \in\left(A_{2} \cap \tilde{A}_{2}\right)
$$

where $\mathrm{m}$ is an integer between zero and $\left[\min \left(l_{i j}, l_{j i}\right)-1\right]$

The total time required can be calculated using the linear programming equation as can be seen in Equation (6).

$$
F(\mathbf{x}, \mathbf{y}, \mathbf{z})=\sum_{n=1}^{N\left(\mathbf{x}, \mathbf{y}, \mathbf{z}, T, A_{1}\right)}\left(t_{n}^{\text {out }}-t_{n}^{\text {in }}\right)
$$

Where $N\left(\mathrm{x}, \mathrm{y}, \mathrm{z}, \mathrm{T}, \mathrm{A}_{1}\right)$ Is the total number of vehicles passing through the area during time $[0, \mathrm{~T}]$;

$t_{n}^{\text {out }}$ is the time of $n^{\text {th }}$ vehicle to leave the area and $t_{n}^{\text {in }}$ is the time of $n^{\text {th }}$ vehicle to enter the area. The difference from these two time is travel time from $n^{\text {th }}$ vehicle for travelling in this discussion. This equation also takes into account the waiting time in the queue that can be formulated using Equation (7).

$$
\min F(\mathbf{x}, \mathbf{y}, \mathbf{z})=\sum_{n=1}^{N\left(\mathbf{x}, \mathbf{y}, \mathbf{z}, T, A_{1}\right)}\left(t_{n}^{\text {out }}-t_{n}^{\text {in }}\right)
$$

Where

$$
\begin{aligned}
& \bar{T}_{i j} / n \leq y_{i j}-x_{i j} \leq \hat{T}_{i j} / n, \quad(i, j) \in A_{2} \\
& z_{i j}^{1} \leq z_{i j}^{2} \leq \cdots \leq z_{i j}^{l_{i j}},(i, j) \in A_{2} \\
& z_{i j}^{l_{i j}-m}+z_{j i}^{l_{j i}-m} \leq 1,(i, j) \in\left(A_{2} \cap \tilde{A}_{2}\right), \mathrm{m}=0, \cdots, \min \left(l_{i j}, l_{j i}\right)-1
\end{aligned}
$$

The Research Framework can be seen in Fig. 4.

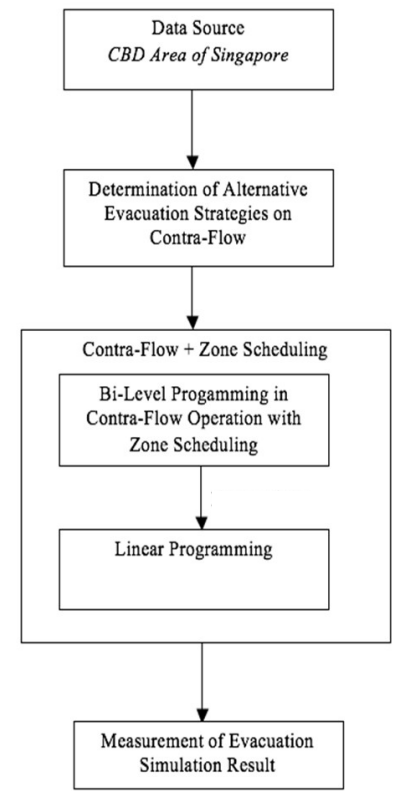

Fig. 4. Research Framework

In Figure 4. We can see that the data used is CBD Area of Singapore. The process begins with formulating a contra-flow strategy to be tested. There are 4 (four) Contra-Flow strategies to be used: All Lanes Outbound, One lane reversed, one lane inbound for emergency / service vehicle entry only, One lane reversed, one lane inbound for traffic only, and One lane reversed and use of outbound left shoulder lane. The ContraFlow problem with Zone Scheduling is basically a matter of BiLevel Programming.

Bi-Level programming model is considered as the most suitable model for transportation investment decision making problem because the bi-level structure reflects the fact that there are two types of decision makers in the transportation system: one side decides the configuration of the evacuation transport route and the other decides about the current pattern in the network.

The general form of bi-level programming model can be written as follows [20]

$$
\begin{aligned}
& \min _{x} F(x, y) \\
& \text { subject to } \mathrm{G}(\mathrm{x}, \mathrm{y}) \leq 0
\end{aligned}
$$

Where y completes:

$$
\begin{aligned}
& \min _{y} f(x, y) \\
& \text { subject to } \mathrm{G}(\mathrm{x}, \mathrm{y}) \leq 0
\end{aligned}
$$


The above equation $[F(x, y)]$ Defines the upper-level problem where the vector $\mathrm{x}$ decision represents the decision on the configuration of the evacuation transport route. The bottom equation $[f(x, y)]$ States the issue of lower level (lower level problem) where the vector y decision states the current pattern in the network.

Upper level is an integer programming model that aims to minimize travel time by integrating contra-flow with zone scheduling while lower level is a traffic simulation model that measures the response of users to the solution offered and this lower level can be ignored.

\section{CONCLUSIONS}

The conclusions of this research are as follows. First, the main problem that often faced related to disaster traffic management is a strategy related to efforts to improve the distribution of space and time based on traffic volume. Second, Contra-Flow itself is basically the arrangement of In-Bound line and Out-Bound line which has several scenarios while the zone scheduling regulates the utilization of each path (zone) to avoid congestion during evacuation process, where the ultimate goal is the creation of safe city as part from smart city that can minimize the occurrence of delay and maximize security. Third, this research framework aims to build a new model to optimize the evacuation process using the Contra-Flow and Zone Scheduling methods in Disaster Management for Smart City

\section{References}

[1] A. Caragliu, C. D. Bo, and P. Nijkamp, "Smart City in Europe",Journal of Urban Technology, vol.18, pp. 65-82, 2011

[2] S.P. Mohanty, U. Choppali, and E. Kougianos, "Everything You Wanted to Know About Smart Cities: The Internet of Things is The Backbone",IEEE Consumer Electronics Magazine, vol.5, pp. 60-70, 2016

[3] M. Lacinak and J. Ristvej, "Smart City, Safety, and Security",Procedia Engineering, vol.192, pp. 522-527, 2017

[4] Centre of Regional Science Viena, Smart Cities-Ranking of European Medium-Sized Cities, 2007

[5] F. Vitalij, A. Robnik, and T. Alexey, "Safe City-And Open and Reliable Solution For A Safe and Smart City",Elektrotehniski Vestnik, vol.79, pp. 262-267, 2012

[6] L. Goodwin and P. Pisano, Current Practices in Transportation Management During Inclement Weather, Institute of Transportation Engineers Annual Meeting, Mitretek Systems ITS Division, 2002
[7] Texas Department of Transportation, I-37 Hurricane Shoulder Evacuation Lane. http://www.cctexas.com/files/g8/EvacLanebrochure\%20.pdf, 2007

[8] B. Wolshon, "Safe City-And Open and Reliable Solution For A Safe and Smart City",Elektrotehniski Vestnik, vol.79, pp. 262-267, 2012

[9] L. Stephen, L,Evaluation of Different Contra-Flow Strategies for Hurricane Evacuation in Charleston, South Carolina, Clemson University, 2007

[10] T. Petrov, M. Dado, and K. E. Ambrosch, "Computer Modelling of Cooperative Intelligent Transportation Systems", Procedia Engineering vol. 192 , pp. 683-688, 2017

[11] A.S. Knapper, and K. A. Brookhuis,"Field Research Concerning ContraFlow as A Measure for Massive Evacuation",Procedia Engineering, vol. 3, pp. 77-86, 2010

[12] A. Cuesta, O. Abreu, A. Balboa, and D. Alvear, "Real-Time Evacuation Route Selection Methodology for Complex Buildings", Fire Safety Journal, vol. 91, pp. 947-954, 2017

[13] A. Mondschein and B. D. Taylor, "Is Traffic Congestion Overrated? Examining The Highly Variable Effects of Congestion on Travel and Accessibility",Journal of Transport Geography, Vol. 64, pp. 65-76, 2017

[14] Q. Meng, H. L. Khoo, and R. L. Cheu, "Microscopic Traffic Simulation Model-Based Optimization Approach for Contraflow Lane Configuration Problem",Journal of Transportation Engineering, vol.134, pp. 41-49, 2006

[15] X. Chen and B. Zhan, "Agent-Based Modeling and Simulation of Urban Evacuation Relative Effectiveness of Simultaneous and Staged Evacuation Strategies",Proceedings of 83rd Transportation Research Board, 2004

[16] H.H. El-Sbayti, Optimal Scheduling of Evacuation Operations With ContraFlow,University of Maryland, 2008

[17] D. Xue and Z. Dong,"An Intelligent Contraflow Control Method for RealTime Optimal Traffic Scheduling Using Artificial Neural Network, Fuzzy Pattern Recognition, and Optimization",IEEE Transactions on Control Systems Technology, vol. 8, pp. 183-191. 2017

[18] L. Marek, M. Campbell, and L. Bui, "Shaking For Innovation: The (re) building of a (smart) city in a Post Disaster Environtment", Cities, vol.63, pp. 41-50, 2017

[19] R.E. Hall, B. Bowerman, J. Taylor, J. Todosow, and V. Wimmersperg, "The Vision of a Smart City", Proceedings of 2nd International Life Extension Technology Workshop,pp. 1-7, 2000

[20] Y. Shimizu, Y. Ishizuka, and J. F. Bard, Non Differentiable and TwoLevel Mathematical Programming, Springer Science+Business Media, New York, 1997

[21] A. Minhans, "Formulation of Traffic Management Strategies in Cases of Disasters",SSRN Journal, pp. 1-15, 2010

[22] G. Theodoulou and B. Wolshon, "Alternative methods to increase the effectiveness of freeway contraflow evacuation",Transportation Research Record, 1865, pp. 48-56, 2004 